\title{
A Holistic View on Sustainability in Additive and Subtractive Manufacturing: A Comparative Empirical Study of Eyewear Production Systems
}

\author{
Sam Solaimani ${ }^{1,2, * \mathbb{D}}$, Alireza Parandian ${ }^{3}$ and Nabi Nabiollahi ${ }^{3}$ \\ 1 Center for Marketing and Supply Chain Management, Nyenrode Business University, \\ 3621 BG Breukelen, The Netherlands \\ 2 First Consulting, 1016 BX Amsterdam, The Netherlands \\ 3 Materialise N. V., 3001 Leuven, Belgium; alireza.parandian@materialise.be (A.P.); \\ nabi.nabiollahi@materialise.be (N.N.) \\ * Correspondence: s.solaimani@nyenrode.nl
}

check for updates

Citation: Solaimani, S.; Parandian, A.; Nabiollahi, N. A Holistic View on Sustainability in Additive and Subtractive Manufacturing: A Comparative Empirical Study of Eyewear Production Systems. Sustainability 2021, 13, 10775. https:// doi.org/10.3390/su131910775

Academic Editors: Mohammad Reza Khosravani and Payam Soltani

Received: 12 August 2021

Accepted: 24 September 2021

Published: 28 September 2021

Publisher's Note: MDPI stays neutral with regard to jurisdictional claims in published maps and institutional affiliations.

Copyright: (c) 2021 by the authors. Licensee MDPI, Basel, Switzerland. This article is an open access article distributed under the terms and conditions of the Creative Commons Attribution (CC BY) license (https:// creativecommons.org/licenses/by/ $4.0 /)$.

\begin{abstract}
To achieve sustainability across the product life cycle, attention to the production process is a prerequisite. As a result of technological advancements, innovation and inventions in production methods are in full swing. Production methods that enable mass customisation (MC) are one of the recent developments in the production domain. This study aims to empirically explore the sustainability impact of two MC-oriented production methods, namely, additive manufacturing (i.e., Selective Laser Sintering) and subtractive manufacturing (Computer Numerical Control Milling) within two complete production lines (i.e., from raw material to assembly) for a wearable product. In the context of the triple bottom line framework, the production lines are analysed from an economic, environmental, and social standpoint. A Discrete-Event Simulation (DES) is used to quantify and compare both production systems with their inherent variability in a dynamic setting of fluctuating order volume and diversity. The findings of the simulation are qualitatively evaluated using expert interviews. This study provides a detailed insight into several sustainability trade-offs in production systems where additive and subtractive manufacturing are involved.
\end{abstract}

Keywords: additive manufacturing; computer numerical control; sustainability; simulation; holistic assessment; mass customisation

\section{Introduction}

Attention to sustainability in manufacturing is increasing, and the reasons for this are manifold [1-4]. First, there are more and more policies and regulations that encourage, and sometimes force, firms to operate without damaging the environment, community, and economies [5], such as the European Union's Sustainable Consumption and Production (SCP) Action Plan (Articles 191 to 193 of the Treaty on the Functioning of the European Union, available at: https:/ / www.europarl.europa.eu/factsheets/en/sheet/77 / sustainable-consumption-and-production (accessed on 10 August 2021)) and the USA's ASTM E60.13 Standards (the sustainable manufacturing standards of The American Society for Testing and Materials (ASTM) are available at: https://www.nist.gov/el/systemsintegration-division-73400/sustainable-manufacturing-standards-related-astm (accessed on 10 August 2021)). Second, more firms find new ways and best practices to generate business (or economic) value with sustainability measures by, for instance, minimising, reusing, or recycling waste [6,7]. Third, environmental responsibility and green manufacturing have an increasing impact on consumers' ecological behaviour and purchase decisions [8,9].

Mass customisation (MC) is a production paradigm that is gaining more traction with the prevalence of advanced manufacturing technologies and Industry 4.0. MC refers to 
the capability to reliably offer a high volume of different product options in a relatively large market that demands customisation without substantial trade-offs in cost, delivery, and quality [10]. To do so, according to [11] (p. 315), "all operations are performed within a fixed solution space, characterised by stable but still flexible and responsive processes". The approach provides flexibility to customers by allowing them to specify their individual needs and combines that with the cost-efficiency of mass production when a more optimised inventory management, logistics and transportation can be achieved [12]. However, when viewed from a sustainability perspective, there are at least two main concerns.

First, it is noteworthy that sustainable manufacturing is defined as "the ability to smartly use natural resources for manufacturing, by creating products and solutions that, thanks to new technology, regulatory measures and coherent social behaviours, can satisfy economic, environmental and social objectives, thus preserving the environment, while continuing to improve the quality of human life" [3] (p. 85). Hence, sustainability is about balancing economic, environmental, and social aspects [13-15]. However, the literature mainly focuses on the economic aspect of sustainability, and the environmental and social aspects are relatively under-researched [15-17].

Second, the researchers' views on MC's economic, social, and environmental impact are far from unanimous. For instance, while $\mathrm{MC}$ is considered to contribute to sustainability by, among other things, reducing material waste, enabling eco-friendly printing, repairability, and reusability, and improving operational flexibility [18,19], it raises an array of challenges, e.g., a high degree of customisation requires higher material usage, which leads to a negative impact on the environment [20]. The same variability in the process complicates the optimisation of energy consumption, material usage, logistics, and reusability $[19,21]$. Additionally, from an economic viewpoint, cost efficiency associated with standardisation is sacrificed to gain production flexibility [22].

Limited empirical studies on sustainability in MC and inconsistent extant views on the matter has led scholars and practitioners to call for more research, especially on quantifying the production process and its impact on sustainability [21,23]. It has been argued that, for a better understanding of the sustainability trade-offs in dynamic MC settings (i.e., to what extent gains in one parameter, such as product variety, leads to a loss in another variable, such as energy consumption), insight into the production planning and control is critical $[24,25]$. However, our current understanding of production and planning trade-offs and their impact on sustainability is limited, partly due to a lack of access to empirical data and the complex process of data collection and analysis [26]. Practically speaking, operations and production practitioners are hampered in their decision-making and transformation towards sustainable manufacturing without a detailed, holistic understanding of the MC production system and its dynamic environment.

This study attempts to identify and quantify the trade-offs in MC production, thereby measuring and comparing the sustainability impact of two MC production methods, i.e., additive manufacturing (AM) and milling enabled by Computer Numerical Control (CNC). Comparing AM and more traditional machining manufacturing methods is common in comparative studies [27-29], and more and more studies emphasise the need for an empirical quantification of the sustainability trade-offs and challenges [30,31]. Accordingly, in this study, a holistic approach is adopted, wherein the entire production line (of a single plastic-based product) is explored, and the sustainability impact, reflected by economic, environmental, and social parameters, is empirically quantified and measured.

The remainder of the paper provides a brief discussion of AM and CNC milling and their sustainability impact. Next, the research method that is based on Discrete-Event Simulation (DES) is elaborated. The findings, including the trade-offs across the production line in AM and CNC milling settings, are discussed. The paper concludes with a higherlevel synthesis of the results and their practical implication, along with the limitations of this study and potential future research topics. 


\section{Mass Customisation Production Methods and Sustainability}

Within the realm of MC, different types of customisation are distinguished. Gilmore and Pine (1997) [32] refer to four approaches where the different extents of customer involvement in design and production and use are considered, namely: (i) Standard offering designed in such way that users can alter it themselves (i.e., called adaptive); (ii) A standard product presented differently to different customers (i.e., cosmetic); (iii) Uniquely customised goods and services without customers awareness (i.e., transparent); (iv) Dialogue with customers to help them articulate their needs and identify the precise offering that fulfils those needs (i.e., collaborative). More specifically, [33] (pp. 612-613) combine two dimensions of customer involvement and the type of modularity across four stages of the production cycle (i.e., design, fabrication, assembly, and use) to conceptualise four archetypes of MC configuration, including: (i) Fabricators, where customers are involved in the early design phase, and where modular components are modified in fabrication to fit customers specific needs; (ii) Involvers, where customers are involved early in the process, but customisation is achieved by combining standard models, and no new modules are fabricated; (iii) Modularisers, where interchangeable modules are developed and customers do not specify their unique requirements until the assembly and use stage; (iv) Assemblers, where customers can choose from a wide range of the pre-determined set of features. It is worth noticing that this study focused on the most intensive level of customer involvement and collaboration ('collaborative approach') with an early cut-to-fit (i.e., the dimensions of a module need to be altered before being combined with other modules. It is used where products have unique dimensions such as length, width, or height; for example, eyeglasses [34]) modularity approach ('fabricator archetype').

In the past decades, manufacturers have increasingly used computer-controlled tools and productions systems to transform digital designs into physical products, a trend that [35] termed as 'digital fabrication'. The two most common MC methods in digital fabrication are additive and subtractive manufacturing. Additive manufacturing (AM) is a "set of emerging technologies that produce three-dimensional objects directly from digital models through an additive process, particularly by storing and joining the products with proper polymers, ceramics, or metals" [36] (p. 8). AM technology consists of three necessary steps, including (i) a computerised 3D solid model, which is developed and converted into a standard AM file format. (ii) The file is sent to an AM machine, where it is manipulated, e.g., by changing the position and orientation of the part or scaling the part, and (iii) the part is then built layer by layer on the AM machine [37] (p. 1192). However, different AM technologies (e.g., fused deposition modelling, inkjet printing, stereolithography) build and consolidate layers differently, i.e., some use thermal energy from laser or electron beams, and other processes use inkjet-type printing heads to accurately spray binder or solvent onto powdered ceramic or polymer [35,37].

The AM technology that this study aims to focus on is Selective Laser Sintering (SLS). SLS is "a solid freeform fabrication technique consisted of building a three-dimensional object layer by layer out of a powder selectively fused by laser radiation. Under the laser radiation, the powder partially melts. The liquid formed by the molten material binds the surrounding powder and solidifies when the temperature decreases, which leads to consolidation" [38] (p. 117). As such, separated parts can be consolidated into single objects with a complex geometry, while the raw material, material waste, energy, and fuel can be kept at a minimum $[39,40]$. However, it has been argued that AM in general and SLS specifically might not have the edge on traditional manufacturing when the entire operating process is considered, such as, for instance, when warm-up and cool-down stages are included in the analysis [37,41].

In contrast to $\mathrm{AM}$, subtractive manufacturing (SM) is based on machining, using machines to cut away from a block of solid material and shape them into components with techniques such as milling, turning, sawing, drilling, and grinding [42]. Other SM technologies include the use of a plasma cutter, electric discharge machining, and a water jet cutter [43]. The motion of the machine tool (e.g., cutting operations by turning, drilling, 
milling, broaching, boring, and grinding) is controlled by its Computer Numerical Control (CNC) unit, and Numerically Controlled (NC) commands are generated on computer-aided design/computer-aided manufacturing (CAD/CAM) systems [44]. The SM technology at the core of this study is milling, in which rotary cutters are used to remove material. Essentially, there are two milling processes, namely, peripheral milling (the cutting teeth are on the periphery of the cutter) and face milling (the cutting teeth are on the face or the end of the cutter) [45]. A discussion on the mechanics of milling cutter is beyond the scope of this study. For more insight consider the work by [44,45].

While there are several insightful studies on the sustainability impact of AM or CNC milling technologies in terms of raw material, amount of waste, energy consumption, carbon footprint, lead-time, and setup-time, e.g., [46-49], a more comprehensive view on sustainability can be gained when different production processes are compared [50].

In the context of metal production, ref. [51] compare the machining approach and an integrated production route based on an additive manufacturing process plus finish machining. In their study, it was suggested not to a priori label a manufacturing strategy as energy- and resource-efficient, since the ecological properties of the involved materials or the processes make AM or SM preferable for only defined production scenarios, as "a function of the amounts of material scraps" [51] (p. 66). In the gear manufacturing setting, ref. [52] compared an AM method (i.e., Laser Engineered Net Shaping, or LENS for short) with CNC machining, and concluded that, by and large, CNC machining is less sustainable, as it involves higher labour and material costs, requires more resources, and consumes more (non-renewable) energy; however, LENS appears to have a higher emission discharge in air and water. Based on a literature review and scenario modelling, ref. [53] compared laser additive manufacturing (LAM) with CNC machining and concluded that LAM may reduce the needed amount of raw material, part inventory, downtime in supply chains of spare parts, and emissions (due to less transportation) more effectively than CNC machining.

In addition to conceptual and analytical studies, there are a few insightful empirical studies, such as the Life Cycle Assessment (LCA) analysis by [28], which compared fused deposition modelling (FDM), inkjet printing (IJP), and CNC milling for two plastic parts. The study concluded that sustainability impact depends on the usage profile (i.e., preventing low utilisation or idling) and the use of a specific machine (e.g., FDM machines had the lowest impact both in maximal utilisation and in minimal utilisation). In general, the study confirms the better sustainability impact of AM in terms of waste. However, higher energy consumption rates and the toxicity of ingredients may overwhelm savings in material impact [28].

Based on an LCA analysis, ref. [27] compared Wire and Arc Additive Manufacturing (WAAM) (i.e., a metal 3D printing technique based on robotic welding), green sand casting, and CNC milling in the context of stainless steel production. The study results indicate that "WAAM is more efficient in material use and has the potential to reduce weight by topology optimisation. This relation between weight and environmental impact is linear; if topology optimisation can reach a $20 \%$ reduction in product weight, its impact will be reduced by $20 \%$. The higher the impact of the material, the larger the benefit of WAAM versus green sand casting and CNC milling due to its lower material consumption, and vice versa" (p. 445). Another LCA study by [29] compared SLS machining and forming for aluminium-based components. The results indicated that, only "when weight reduction as high as $50 \%$ and use phase benefits are included, additive manufacturing is preferable over conventional manufacturing if the designed component has to be assembled on an aircraft" (p. 274).

In sum, it can be concluded that different context-dependent findings on the sustainability impact of AM in comparison to other production systems exist. Equally important is that most of the existing studies are not empirical and do not test the concepts and assumptions in real-life settings [26]. This study empirically compares the sustainability 
impact of the AM and CNC milling production lines for a single wearable product. The following section describes the applied methodology.

\section{Research Method}

The simulation-based analysis is a common approach used to study a manufacturing system [54]. A simulation is "an imitation of the behaviour of a real-world process or system over time" [55] (p. 52). Given the variability and dynamics inherent to the multi-machine production process, the DES is used. A DES is "one in which the model is naturally expressed in terms of events (typically interactions among various interesting objects) that happen at specific times" [56] (p. 456). This study focuses on comparing two eyewear production systems (from raw material until assembly) that include $\mathrm{CNC}$ milling with acetate plates and SLS with PA12. While CNC milling is a more traditional production approach than AM, this study focuses on the 'assembly phase' customisation strategy, which refers to standard customisation based on a different combination of standard components [57]. Collecting valid data is considered to be the most challenging step in DES [58]. To overcome the challenge and develop a base model, two European-based manufacturers involved in this study were visited, and multiple individuals with different roles within the factories were interviewed, including business developers, innovation managers, and production managers in both factories. In addition, several process engineers in both plants were consulted several times in both factories to gain access to detailed data on operations.

The production systems involve stochastic processes represented by triangular distribution for machines, changeovers, delays, and switching time, and the interviewed practitioners determined the min, max, and median. Both production lines have a customer order decoupling point (CODP) at the point where semi-finished products are kept in stock. The CODP is "the point in the goods flow where forecast-driven production and customer order-driven production are separated" [59] (p. 212) (see Figure 1 for a graphical representation of the production lines).

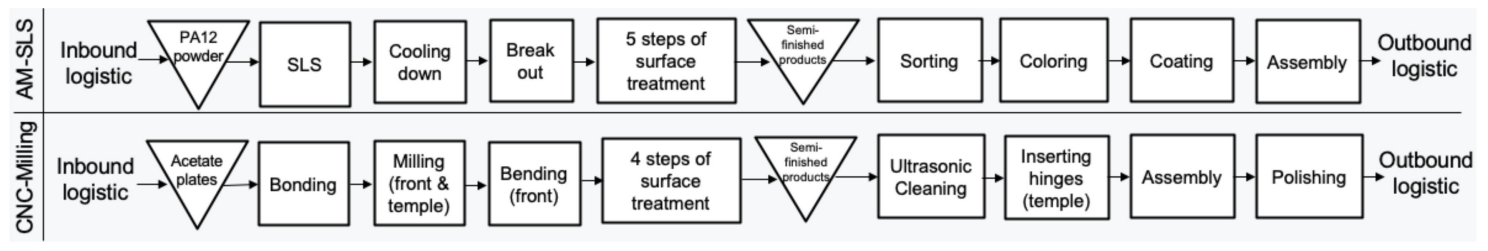

Figure 1. The AM and CNC milling production lines for the eyewear product.

In line with the discussion on sustainable manufacturing in Section 1, the three dimensions of sustainability, namely, economic, environmental, and social, formed the basis of the dependent variables measured with the (i) cost of the work-in-progress (WIP) inventory of the raw material and semi-finished products (euros) and (internal) mean lead time (hour/unit) (from an economic viewpoint), energy consumption (kW) (from an environmental perspective), and manual labour intensity (hours) (from a social perspective). Equally important is that the targeted data were both available and accessible.

The production system capacity, processing time, batch sizes, Minimum Order Quantities (MOQs) are extracted from the interviews. For the AM production, $0.02 \mathrm{Kg}$ PA12 per frame is considered, and at least $20 \mathrm{Kg}$ of PA12 (white color) per batch is the minimum order size to suppliers; in the CNC milling, 20 frames per one acetate plate is considered, and at least, 15 plates per batch can be purchased from the suppliers. Table 1 provides an overview of the default values per process, including whether a machine, labour, or both (in the case of semi-automated processes) are involved, as well as the average rate of energy consumption (i.e., down, idle, and active), processing time per frame or batch, labour time per activity, and frames per batch (a more detailed specification is available upon request). In this experimental setting, the batch sizes are limited to 100 across all the steps in both AM and CNC milling. 
Table 1. Specification of parameters and default values in AM and CNC milling production.

\begin{tabular}{|c|c|c|c|c|c|c|}
\hline & Processes & Machine & Labour & $\begin{array}{c}\text { Energy } \\
\text { Consumption }\end{array}$ & $\begin{array}{l}\text { Processing } \\
\text { Time }\end{array}$ & Labour Time \\
\hline \multirow{8}{*}{ 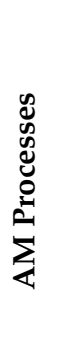 } & SLS & $x$ & $x$ & $10 \mathrm{~kW} / \mathrm{h}$ & $1080 \mathrm{~min} / \mathrm{batch}$ & $60 \mathrm{~min} / \mathrm{batch}$ \\
\hline & $\begin{array}{l}\text { Cooling } \\
\text { down }\end{array}$ & & & 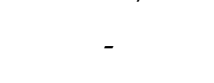 & $1080 \mathrm{~min} / \mathrm{batch}$ & \\
\hline & Breakout & & $x$ & - & - & $10 \mathrm{~min} / \mathrm{batch}$ \\
\hline & Surface treatment & $x$ & $x$ & $12.25 \mathrm{~kW} / \mathrm{h}$ & $600 \mathrm{~min} / \mathrm{batch}$ & $70 \mathrm{~min} / \mathrm{batch}$ \\
\hline & Sorting & & $x$ & - & - & $0.5 \mathrm{~min} /$ frame \\
\hline & Colouring & $x$ & $x$ & $0.4 \mathrm{~kW} / \mathrm{h}$ & $180 \mathrm{~min} / \mathrm{batch}$ & $15 \mathrm{~min} / \mathrm{batch}$ \\
\hline & Coating & $x$ & $x$ & $0.1 \mathrm{~kW} / \mathrm{h}$ & $60 \mathrm{~min} / \mathrm{batch}$ & $10 \mathrm{~min} / \mathrm{batch}$ \\
\hline & Assembly & & $\mathrm{x}$ & & & $2.5 \mathrm{~min} /$ frame \\
\hline \multirow{8}{*}{ 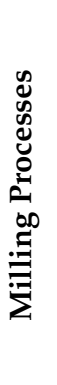 } & Bonding & $x$ & $x$ & $5 \mathrm{~kW} / \mathrm{h}$ & $0.5 \mathrm{~min} /$ frame & $12 \mathrm{~min} / \mathrm{batch}$ \\
\hline & Milling & $x$ & $x$ & $8 \mathrm{~kW} / \mathrm{h}$ & $7 \mathrm{~min} /$ frame & $\begin{array}{l}60 \mathrm{~min} / \text { batch } \\
\text { (switch-over) }\end{array}$ \\
\hline & Bending & $x$ & $x$ & $0.9 \mathrm{~kW} / \mathrm{h}$ & $1 \mathrm{~min} /$ frame & $\begin{array}{l}30 \mathrm{~min} / \text { batch } \\
\text { (switch-over) }\end{array}$ \\
\hline & Surface treatment & $x$ & $x$ & $2.61 \mathrm{~kW} / \mathrm{h}$ & $92 \mathrm{~h} /$ batch & $60 \mathrm{~min} / \mathrm{batch}$ \\
\hline & US Cleaning & $x$ & $x$ & $7 \mathrm{~kW} / \mathrm{h}$ & $60 \mathrm{~min} / \mathrm{batch}$ & $10 \mathrm{~min} / \mathrm{batch}$ \\
\hline & Inserting & $x$ & $x$ & $1 \mathrm{~kW} / \mathrm{h}$ & $5 \mathrm{~min} /$ frame & \\
\hline & Assembly & & $x$ & - & & $0.6 \mathrm{~min} /$ frame \\
\hline & Polishing & & $x$ & - & & $4 \mathrm{~min} /$ frame \\
\hline
\end{tabular}

The simulation is set up as follows: First, based on the insights drawn from interviews, and in line with earlier studies, order 'volume' and 'diversity' are considered as the independent variables, e.g., $[28,47,53]$. The order diversity represents the level of customisation. Using order diversity and order volume enabled four scenarios: (i) A high constant order diversity with an increasing order volume; (ii) A low constant order diversity with an increasing order volume; (iii) A high constant order volume with an increasing order diversity; (iv)A low constant order volume with an increasing order diversity. For each scenario, one full year of production (consisting of 52 weeks, five days per week, and $10 \mathrm{~h}$ per day for both machine and labour) was simulated. Following the interviewees suggestions, a weekly order volume of between 72 and 288 was considered. The order diversity is regarded as a function of shape, colour, and size, with realistic ranges of 1 to 4 shapes, 1 to 6 colours, and 1 to 3 sizes (leading to variation of 3 to 72 stock-keeping units, or SKUs). With an additional Python-based script, random customer orders based on the SKUs were generated to trigger a simulation (see Appendix A).

Second, following the practitioners' suggestions, a representative but simplified production planning and inventory policy were formulated. Throughout the simulation, the manufacturers kept an inventory of raw material and semi-finished products, denoted by RawST and ST, respectively. $\mathrm{F}_{i}$ is the order forecast for month $i$, which is the actual order from the previous month $\left.{ }_{i-1}\right) . \mathbf{R}_{i}$ is the replenishment order for month $i$, which is at the beginning of each month, and $\mathrm{O}_{i}$ is the actual order for month $i$.

At the beginning of the simulation, there were no past orders that could be used as a forecast to produce semi-finished products (i.e., initiating the push system). Hence, a one-week warm-up period was needed to set an initial stock level of semi-finished products given in an input file (the seed values are kept identical for both systems). In compliance with the inventory policy, the semi-finished inventory level at the beginning of each month was checked; if the inventory was less than the forecasted order for the coming month (i.e., $\mathrm{ST}_{i}-1<\mathrm{F}_{i}$ ), the production process would be triggered to replenish semi-finished products (i.e., $\mathrm{R}_{i}=\mathrm{F}_{i}-\mathrm{ST}_{(i-1)}$ ). The raw material inventory level was checked at the beginning of each month. If the inventory was less than the forecasted order for the coming three months (i.e., $\operatorname{RawST}_{(i-1)}<3{ }^{*} \mathrm{~F}_{i}$ ), then the manufacturer ordered new raw material in compliance with the suppliers' MOQ policy. Weekly customer demand (see the earlier discussion on input file based on ranges for volume and diversity) triggered the pull 
regime, where the semi-finished products were further manufactured into final products based on customer orders. If there was a shortage of semi-finished products to fulfil the customer order, a backlog order was sent to the production process (i.e., adding to the queue of the push process).

For simulation, anyLogic (version 8.5.2) simulation tool was used, which allowed the customisation of the pre-existing features with the Java programming language (e.g., the batching, inventory replenishment, MOQ policy, and order completion are coded in Java). Appendix A provides the codes behind the most critical steps in the simulation. Before starting the actual simulation, a dry run in a deterministic environment was conducted to validate the production line's behaviour. To remain confident about the simulation operation, variability was gradually included and, in each step, the results were discussed with the involved practitioners. Once the analysis was completed, a panel of company experts (from both AM and CNC milling) was organised, where the results of this study were presented, and the experts' comments and suggestions were collected. The experts' insights helped us with interpreting the results. In this session, in addition to the roles and functions involved from the early stages of the study, the chief technology officer, research manager, business line director, head of quality and engineering, production management, corporate social responsibility specialists, lean production specialists, and several other C-level managers were also involved. The following section provides the findings.

\section{Results}

The AM and CNC milling production lines are compared in terms of inventory cost (WIP), lead time, energy consumption, and labour intensity.

The analysis shows that, in general, the cost of raw material inventory is higher in the milling process (Figure 2a1,a2). It implies that the CNC milling inventory level is more severely affected by inaccuracy in the demand forecast. One of the experts emphasised the impact of MOQ as the underlying reason: "In CNC milling, the demand forecast error is multiplied by the number of colours because every colour has its MOQ value (CNC milling eyewear innovation manager)" (note that, while AM uses white powder for any type of frame and colours the frames only after the CODP when the actual demand is known, milling needs to acquire coloured plates based on forecasted demand). It is, however, remarkable that a higher diversity of orders seems to have a marginal impact on inventory cost. Given the 'inflexibility' of raw material in the milling operations in producing coloured frames, it can be expected that diversity leads to higher inventory, as more coloured plates need to be stocked. The result shows, however, a slight decrease in cost. Apparently, in scenarios with a higher-order diversity (with order volumes remaining constant), the stock moves faster, implying a slightly higher machine utilisation. Consistently, while the increase in volume has a deteriorating effect on the raw material inventory in $\mathrm{CNC}$ milling, the slope of increase is sharper in low diversity.

The inventory cost of semi-finished goods in AM and CNC milling has similar cost behaviour (i.e., volume seems to be the decisive factor in both). It is noteworthy that there is a lower CNC milling semi-finished inventory level; however, given the fact that an acetate (unpolished but coloured) frame in the semi-finished state has a higher economic value than a white uncoloured 3D printed frame, the inventory 'costs' in the semi-finished stage seems to follow a relatively similar trend. One possible clarification for the higher inventory level in the AM manufacturing line is that the colouring process is organised in batches and, therefore, some parts may remain longer in inventory, waiting to be coloured. As diversity grows (especially in terms of colour: see later discussion on sensitivity analysis), the flow of goods in AM can be expected to congest at the colouring stage, mainly because it is organised in batches. During our expert panel discussion, it was suggested by one of the AM production managers that: "in principle, this impact could be prevented in AM if different machines are used in parallel for colouring. In fact, in reality, multiple concurrent batching is applied to be able to prevent congestion". 
In short, it can be argued that the inventory costs are considerably higher in CNC milling than in the AM manufacturing line, which is not necessarily linked to the complexity of customisation, but rather a higher raw material stock level as a function of the MOQ of the acetate plates in CNC milling.

In terms of lead time, it appears that the lead times for the CNC milling manufacturing line are considerably higher to reach the CODP stage both when the order volume and diversity increases (volume leads to a slightly steeper slope of increase) (Figure 2b1,b2). However, from CODP to release, the effect seems to be partially reversed. An increase in diversity appears to deteriorate the lead time due to lower throughput in the colouring stage. Strikingly, in the high-volume scenarios, non-linear behaviour of lead time in AM can be observed, hinting that there is an optimum extent of volume and diversity. While the scrap rate was beyond the scope of this study, during the expert panel discussion, one of the AM's business line managers emphasised that: "the scrap rates in AM process are considerably higher compared to CNC milling manufacturing and that often in the case of eyewear surface defects only become visible after colouring has taken place". The extent to which the scrap rate would impact the lead time deserves further consideration in future research.

From an energy consumption viewpoint, the AM manufacturing line is more energyefficient than CNC milling across all scenarios. This finding corroborates earlier assumptions and propositions, e.g., [28,47], in that, while CNC milling machines or units are more efficient, the AM production line, including all the pre-processing and post-processing activities, runs more efficiently together. Additionally, CNC milling machines consume as much energy during a change-over (idle state) as when the operation is active, which explains the increasing impact of order diversity on energy consumption in the CNC milling line. It can be observed that, when there is a lower order diversity, the energy efficiency of the CNC milling manufacturing line increases considerably.

During the discussion with the expert panel, a senior AM production line manager confirmed that the findings on energy consumption are in line with his expectations when it comes to the CNC milling and AM as stand-alone technologies. However, it should be noted that "while diversity in shape and size may cause inefficiencies in energy consumption in the CNC milling production line; in AM, the colouring process requires heating of water which can cause inefficiencies as well". Moreover, it was remarked by one of the AM's senior process engineers that "one needs to also take into account the source from which the energy is generated to determine the actual environmental impact". Considering that both factories involved in this study did not necessarily make use of renewable or green energy, the impact of this factor in this study is negligible; however, it is noteworthy that both production lines can reduce carbon footprint in case a switch is made to renewable energy.

Concerning the labour intensity, the CNC milling line appears to be more negatively impacted by order diversity and volume than the AM line, even in the high-volume-lowdiversity settings. It is important to note that manual labour intensity is higher in a CNC milling line, but it shows sudden (steep) growth, particularly when the order size increases. Clarification for the steep rise in the CNC milling line is that, in a high diversity setting, there is a large amount of manual labour required for organising the batch processes during switch-over between shapes and sizes that need to be made in between the orders. Furthermore, the CNC milling process requires many craftsman skills and can become labour intensive in the polishing step. 


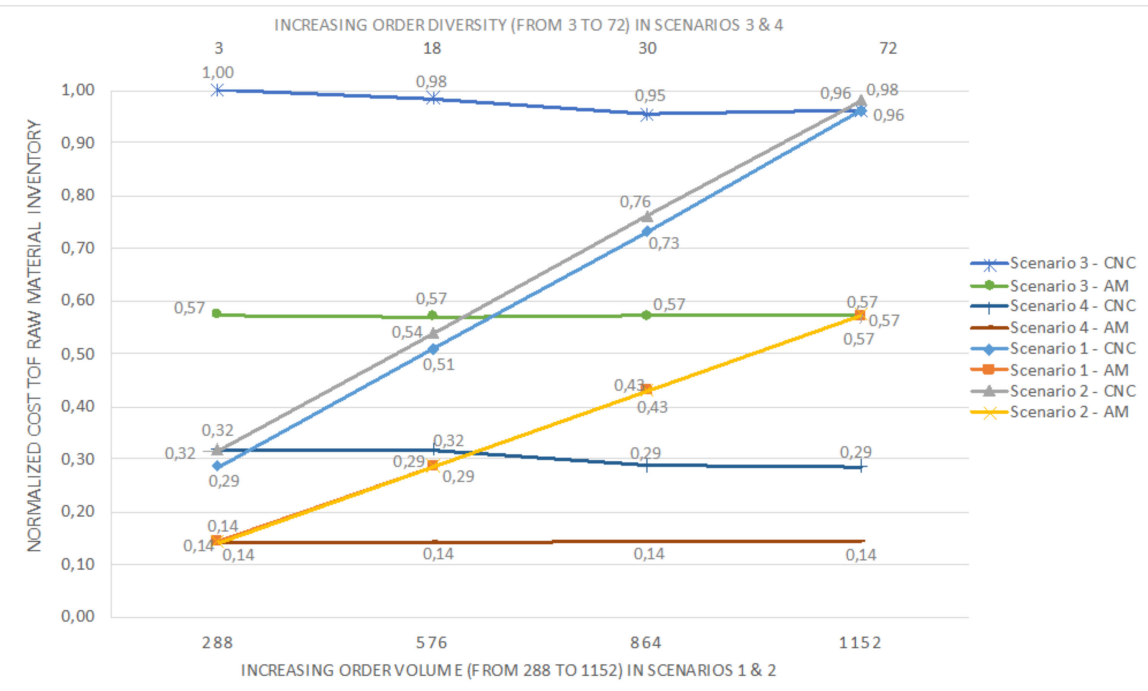

(a1) Raw material inventory

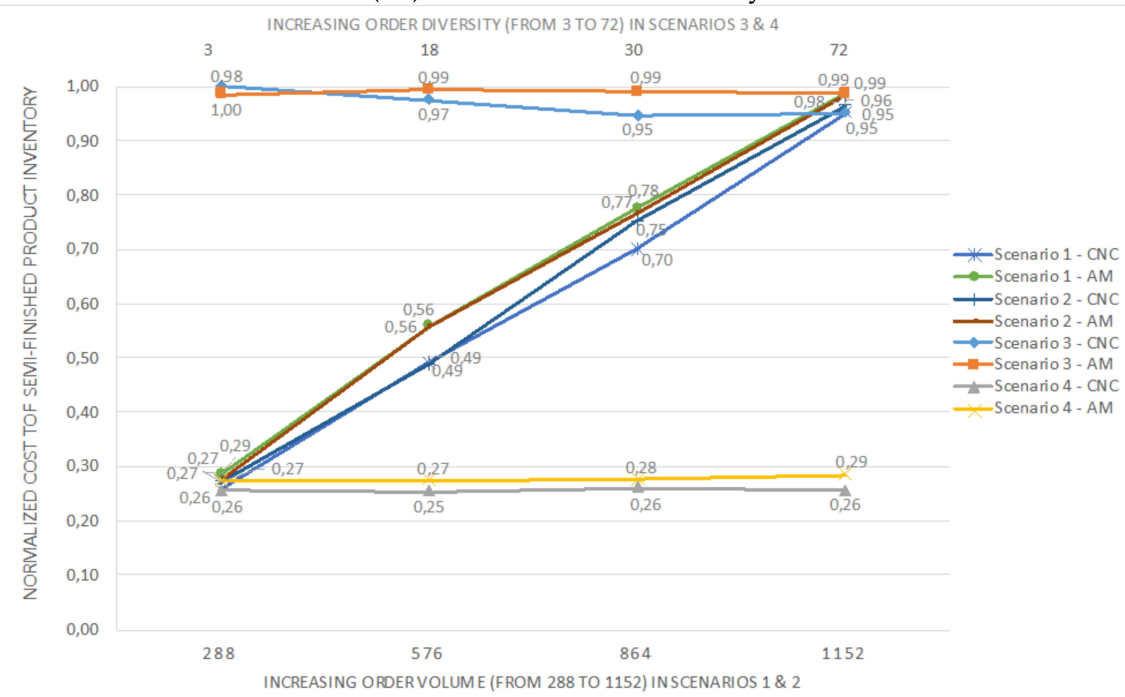

(a2) Semi-finished product inventory

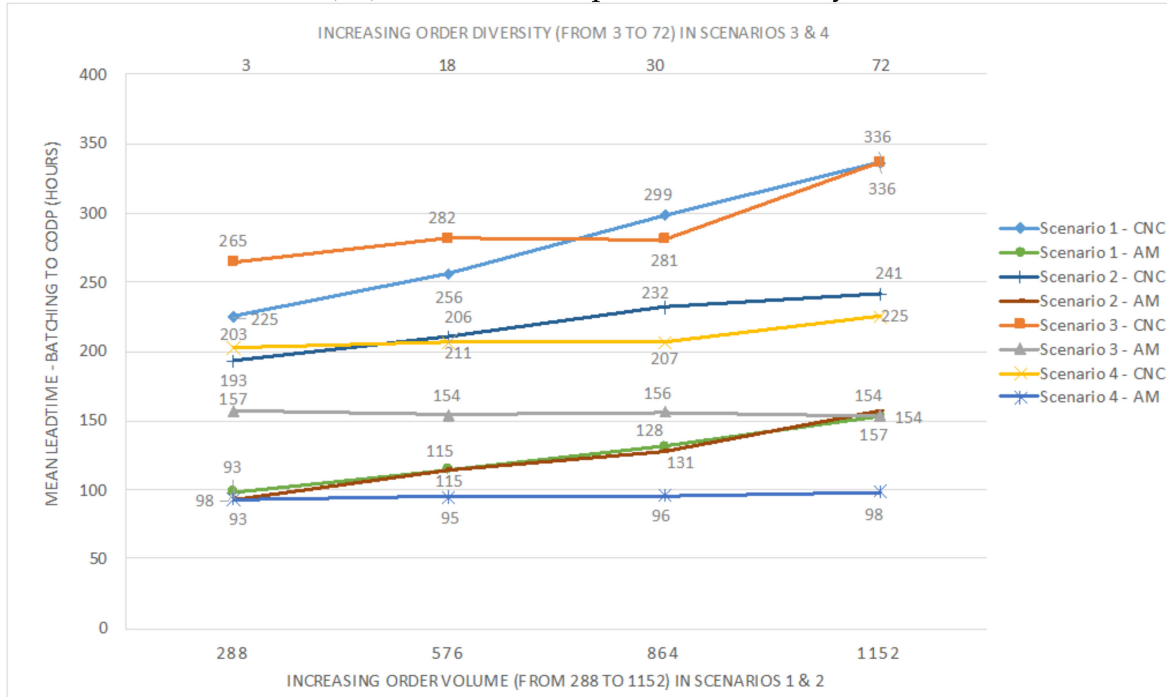

(b1) Batching to CODP

Figure 2. Cont. 


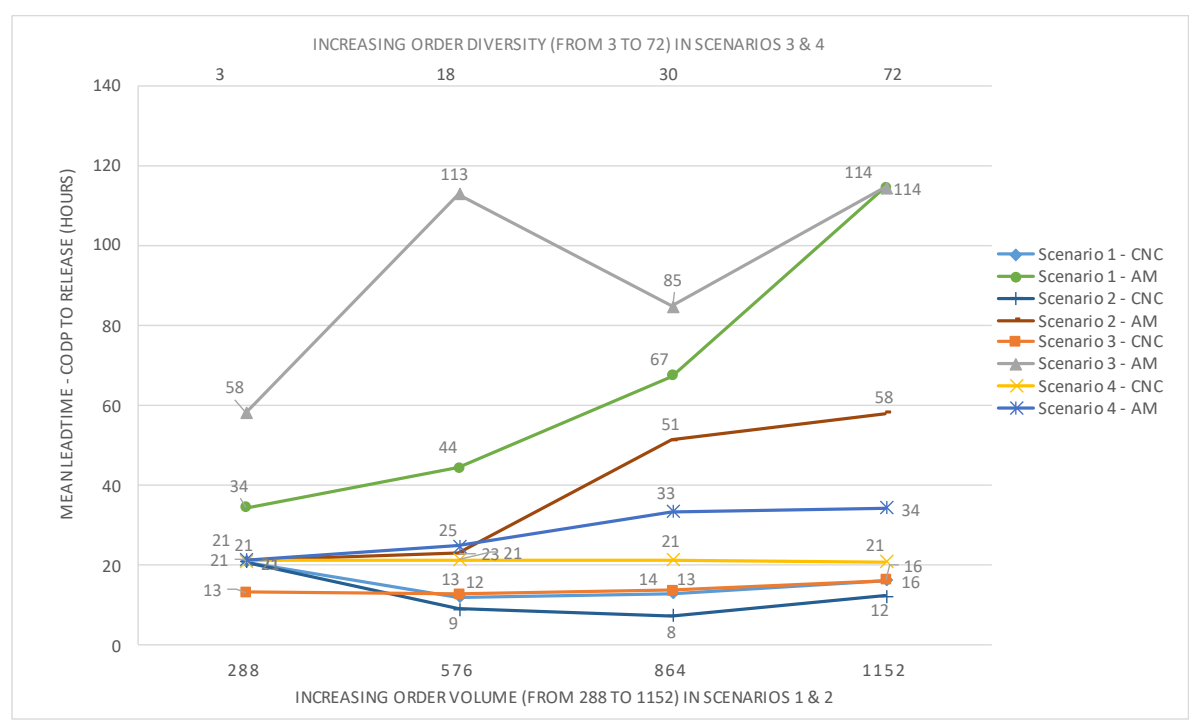

(b2) CODP to release

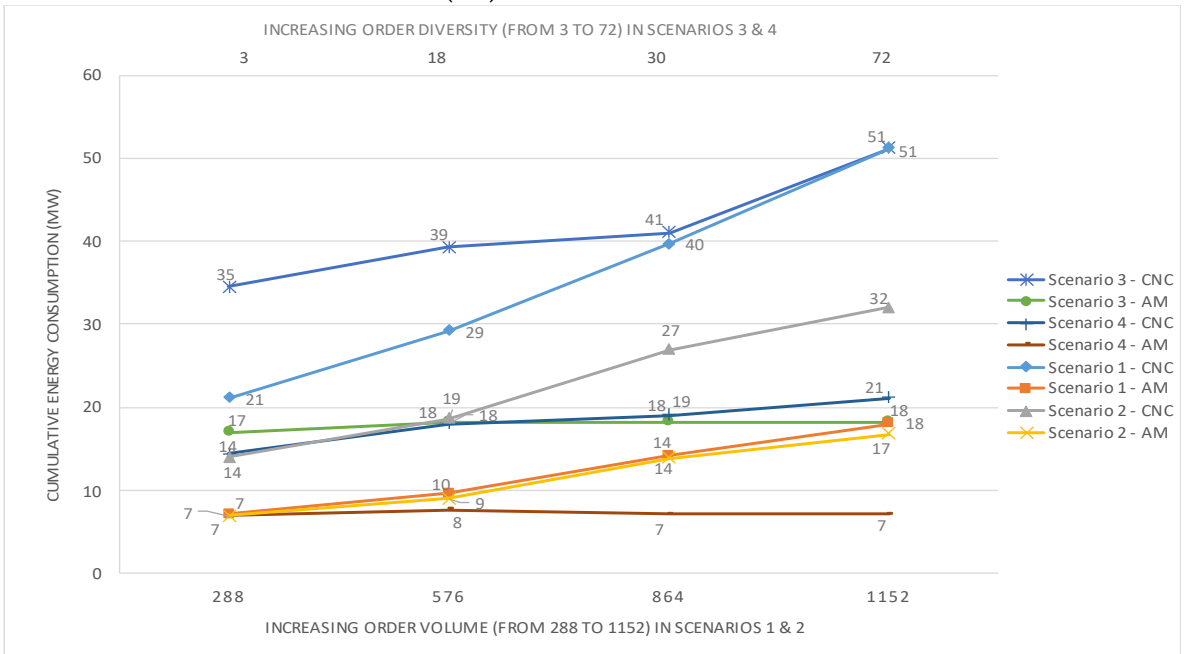

(c) Energy consumption

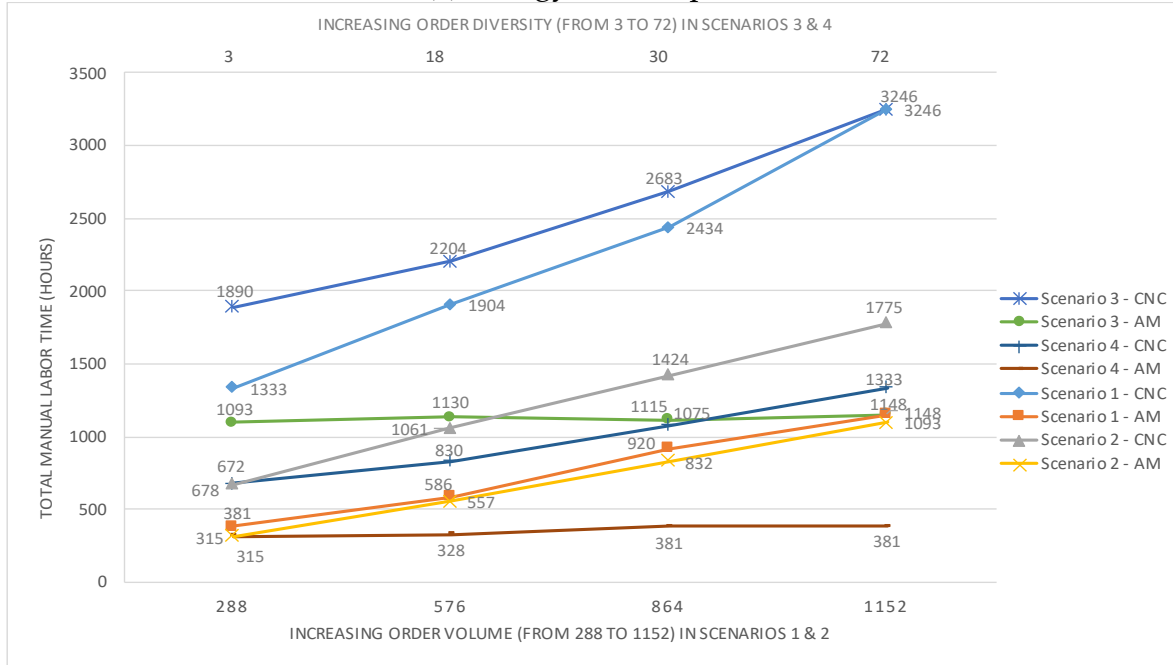

(d) Labour intensity

Figure 2. (a1,a2) Impact of changing order volume and diversity on the WIP inventory cost: $(\mathbf{b} 1, \mathbf{b} 2)$ Impact of changing order volume and diversity on the internal lead-time; (c) Impact of changing order volume and diversity on energy consumption; (d) Impact of changing order volume and diversity on labour intensity. 
As discussed in the previous section, diversity is a compound variable containing shape, colour, and size. To better understand the impact of diversity on AM and CNC milling, a sensitivity analysis is conducted, in which diversity is defined as two shapes, three sizes, and 12 colours (to single out the effect of colour); three shapes, 12 sizes, and two colours (to single out the effect of size); and 12 shapes, three sizes, and two colours (to single out the effect of shape) (Figure 3). The result shows that: (i) There is no significant impact on the inventory cost in both technologies; (ii) CNC milling appears to be sensitive to the increasing complexity of orders in terms of shape and size (particularly from batching to CODP) as a result of change-over-time, while, conversely, AM shows a high sensitivity to increasing order diversity in terms of colour variation as a result of inefficiency in batching in the colouring process between CODP and product release; (iii) While energy consumption in AM seems not to be affected by any of the features, increasing order complexity in terms of shape and size negatively impacts energy consumption in the CNC milling manufacturing line (higher volumes, however, seem to have a positive impact on production flow); (iv) While CNC milling production line shows a relatively high sensitivity to shape and size as a result of manual finishing techniques and craftsmanship, AM seems to show a modest increase in labour intensity when the number of colours is increased (it stabilises when the volume grows).

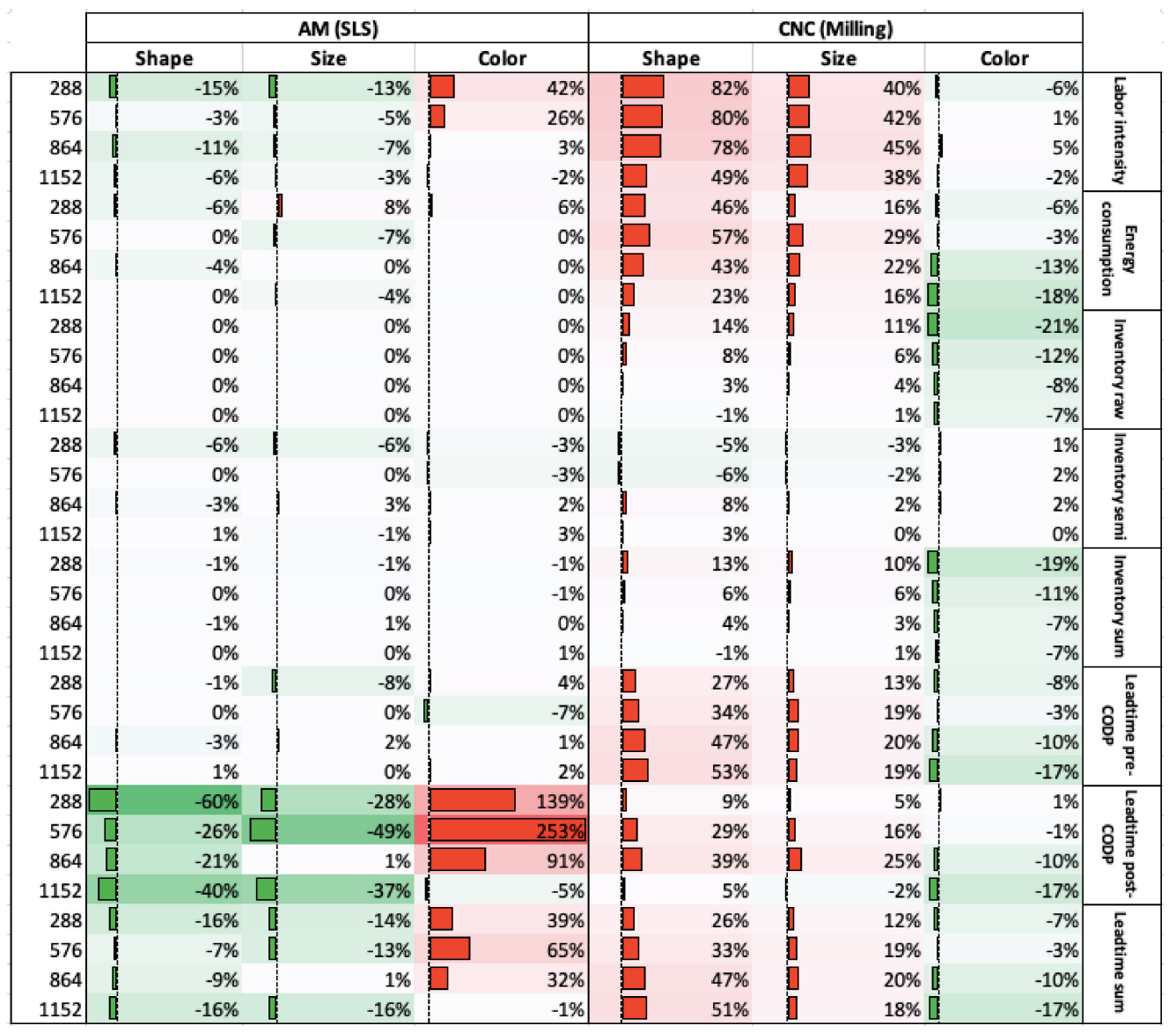

Figure 3. Sensitivity analysis on orders' colour, size, and shape with changing order volumes.

\section{Discussion}

The urgency of sustainable operations is pressing. A critical step in achieving sustainability is the quantification of operations and empirical analysis of waste and inefficiencies. However, for such an approach to be most effective, a holistic view of processes and production needs to be adopted. Sustainability impact is best measured when all the interactions and independencies within the system are considered. In practice, such studies are scarce 
because operations and production are often complex dynamic systems, access to, and collection of, reliable data is difficult, and a relatively limited amount of methodological approaches can be used in such complex and dynamic settings.

This study is among the first attempts to empirically examine and juxtapose the entire production lines in an additive and subtractive manufacturing setting from an economic, environmental, and social standpoint. While the findings indicate a better sustainability performance for additive manufacturing, corroborating with some earlier studies $[28,37,60,61]$, the detailed empirical nature of the study allowed for some valuable nuances and conditions, including: (i) From an economic viewpoint, AM seems to perform better than $\mathrm{CNC}$ milling both in terms of inventory cost and lead-time; however, there appears to be a trade-off between lead-time and order diversity in CNC milling (i.e., accepting lower diversity in shape and size would accommodate faster lead-times); (ii) From an environmental viewpoint, the AM production line consumes less energy in general than CNC milling, but order diversity seems to have a higher deteriorating effect in both production lines; (iii) From a social viewpoint, CNC milling requires more manual labour, order diversity seems to have a worsening impact in both $\mathrm{AM}$ and $\mathrm{CNC}$ milling production lines, and changing order size leads to a sudden steep increase in the manual process involved in the $\mathrm{CNC}$ milling production line. In practical terms, this study encourages the operations and production of professionals to evaluate the design, planning, and control of their production system from an economic, environmental, and social perspective, simultaneously, and to pay attention to the possible conflicting interaction effects between sustainability factors and how external forces and environmental dynamism may reinforce or balance the effects.

\section{Limitations and Future Research Directions}

To understand the finding of this study correctly, some limitations and simplifications are essential to mention. First, some production planning and control aspects, e.g., inventory policy and demand forecast, and production process and procurement conditions, are slightly simplified to preserve the 'interpretability' of the results. While simplifying policies is common in simulation-based studies, care is taken to maintain a representative reconstruction of reality by validating the simplifications with practitioners and experts. Sensitivity analyses were conducted to check the results' robustness and alleviate some uncertainties caused by the limitations and simplifications. Moreover, simulation studies are commonly focused on a single context, which is the production of a wearable product in this study. However, in this study, two different production lines and methods are compared, providing a rich and comprehensive empirical insight into the problem. As argued earlier, without such specification and contextualisation, the findings are prone to the fallacy of oversimplification or overaggregation, losing essential nuances of such a dynamic production environment.

There remains several fruitful areas for future explorations. Among others, the application of AM and CNC milling, or other additive and subtractive methods for that matter, in different contexts or applications, such as the medical, aeronautic, and automotive (where a varying degree of requirements including durability, rigidity, accuracy, aesthetic, and suchlike are at play) can be further explored. While the broad scope of this study is unique (i.e., with a simultaneous focus on the inventory level and its cost, lead time, energy consumption, and the labour intensity), other relevant factors can be considered in the future, including the rate of water wastage, material toxicity, carbon dioxide emission, scrap, and several social aspects including employees' performance, fatigue, and distortion. Although challenging from a data collection and data reliability viewpoint, shifting the level of analysis from a multi-machine to a broader multi-factory view, or even to the supply chain network, is another research direction that helps to achieve a more accurate understanding of the sustainability impact [50,62-64]. In this regard, the collaboration between supply chain actors can act as a catalyst to promote innovative production strategies and a combination of production approaches favouring sustainability [65,66]. Moreover, a more detailed understanding of the sustainability footprint of hybrid manufacturing workflows 
(i.e., combining additive and subtractive techniques) is an interesting research direction [67]. Finally, the impact of additive manufacturing on Lean management in achieving higher sustainability performance, in terms of waste minimalization, process flow, quality, and employee's safety, is another potential direction for future research [68-70].

Author Contributions: Conceptualization, S.S.; methodology, S.S. and A.P.; formal analysis and visualization, S.S., A.P. and N.N.; formal analysis; writing — original draft preparation, S.S.; writingreview and editing, S.S., A.P. and N.N. All authors have read and agreed to the published version of the manuscript.

Funding: This research received no external funding.

Institutional Review Board Statement: Not applicable.

Informed Consent Statement: Not applicable.

Data Availability Statement: The data will be made available upon request to the corresponding author.

Acknowledgments: The authors would like to thank Jingzi $\mathrm{Xu}$ and Valérie Vriamont for their continued support and constructive suggestions throughout the data collection process.

Conflicts of Interest: The authors declare no conflict of interest.

\section{Appendix A. Overview of the JAVA Codes for the Critical Processes}

Python program for generating SKUs

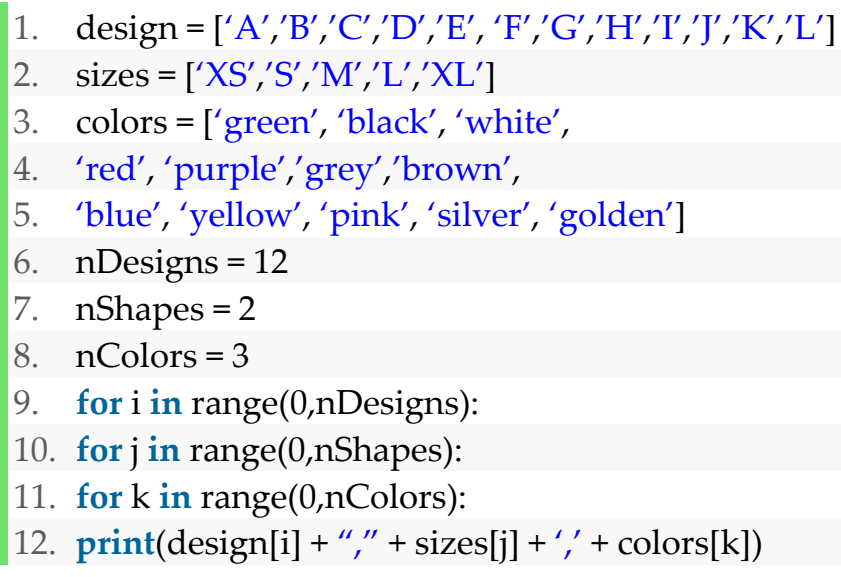

The generated list is copied to a file and then used as an input for AnyLogic simulation Java snippet in AnyLogic for randomizing the orders:

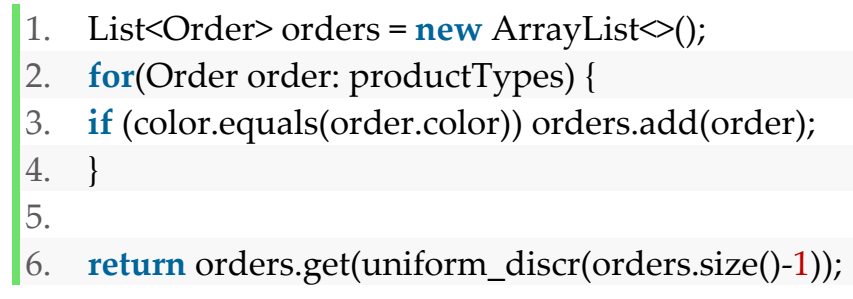

Weekly order event: 
1. $\quad$ int orderSize $=0$;

2. totalOrders++;

3.

4. for(Order order : productTypes) \{

5. int $\mathrm{c}=$ (int) OrderArrivalMean;

6. orderSize $+=c$;

7. weeklySupplyMaterials.put(productTypes.indexOf(order), c);

8. int $\mathrm{s}=$ currentMonthVolumeInitMaterial.get $($ productTypes.indexOf(order $))+\mathrm{c}$;

9. currentMonthVolumeInitMaterial.put(productTypes.indexOf(order), s);

10. $\}$

11. batchOrderSize.add(orderSize);

12. totalOrderedCheck $+=$ orderSize;

Inventory check to pull from semi-finished products if possible:

1. for(Order order : productTypes) \{

2. int need $=$ weeklySupplyMaterials.get(productTypes.indexOf(order));

3. int all = SemiFinishStoreST.get(productTypes.indexOf(order));

4. if (need $<=$ all) \{

5. SemiFinishStoreST.put(productTypes.indexOf(order), all-need);

6. removeFromSemiFinishInventory(order.sku, need, totalOrders);

7. $\}$ else \{

8. SemiFinishStoreST.put(productTypes.indexOf(order), 0 );

9. removeFromSemiFinishInventory(order.sku, all, totalOrders);

10. enterManufacturingSemiProducts(need-all, order, true, totalOrders);

11. $\}$

12. $\}$

Monthly event to refill the raw inventory based on the MOQ (The code below is for $\mathrm{AM}$, a similar approach with different colors is used for $\mathrm{CNC}$ )

1. int fWhite $=0$;

2. for(Order order : productTypes) \{

3. fWhite $+=$ initVolumeMaterialByStart.get(productTypes.indexOf(order));

4. $\}$

5.

6. double $\mathrm{fc}=3$; // forecast coefficient

7.

8. if $\left(\mathrm{fc}^{*} \mathrm{fWhite}>(\right.$ RawMaterialStoreST*MOQToProduct $\left.)\right)\{$

9. int orderSize $=\left(\mathrm{fc}^{*} \mathrm{fWhite}-\right.$ RawMaterialStoreST ${ }^{*}$ MOQToProduct $) /$ MOQToProd uct;

10. reOrderSource.inject((orderSize $>\mathrm{MOQ}$ ? orderSize : $\mathrm{MOQ})$ );

11. \}

An example of a batching code for sorting products for final set of operations in AM:

1. if (orderComplCollection.get(agent.orderIndex) == null)

2. orderComplCollection.put(agent.orderIndex, new ArrayList $<>())$;

3. orderComplCollection.get(agent.orderIndex).add(agent);

4.

5. if (orderComplCollection.get(agent.orderIndex).size() $>=$

6. batchOrderSize.get(agent.orderIndex))

7. \{ 


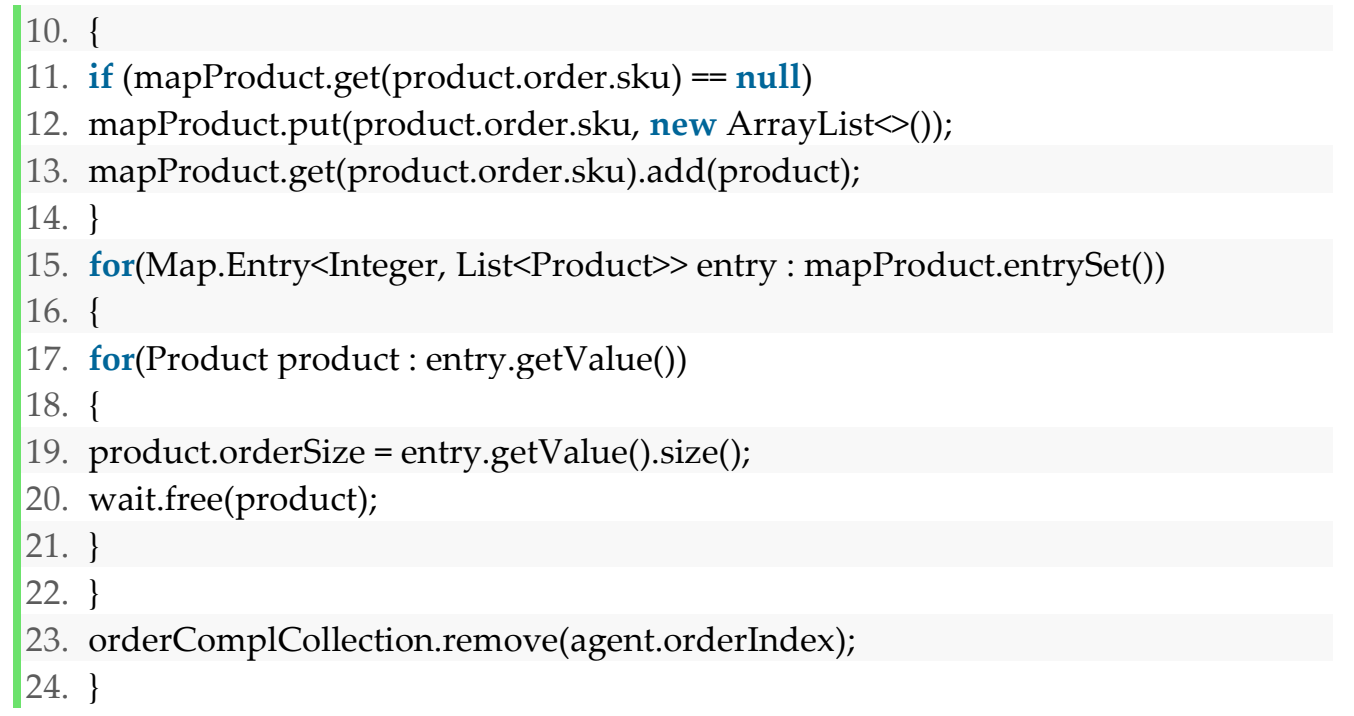

\section{References}

1. Shankar, K.M.; Kumar, P.U.; Kannan, D. Analyzing the drivers of advanced sustainable manufacturing system using AHP approach. Sustainability 2016, 8, 824. [CrossRef]

2. Kishawy, H.A.; Hegab, H.; Saad, E. Design for sustainable manufacturing: Approach, implementation, and assessment. Sustainability 2018, 10, 3604. [CrossRef]

3. Garetti, M.; Taisch, M. Sustainable manufacturing: Trends and research challenges. Prod. Plan. Control 2012, 23, 83-104. [CrossRef]

4. Qureshi, M.I.; Khan, N.; Qayyum, S.; Malik, S.; Hishan, S.S.; Ramayah, T. Classifications of sustainable manufacturing practices in ASEAN region: A systematic review and bibliometric analysis of the past decade of research. Sustainability 2020, 12, 8950. [CrossRef]

5. Mani, M.; Madan, J.; Lee, J.H.; Lyons, K.W.; Gupta, S.K. Sustainability characterisation for manufacturing processes. Int. J. Prod. Res. 2014, 52, 5895-5912. [CrossRef]

6. Despeisse, M.; Mbaye, F.; Ball, P.D.; Levers, A. The emergence of sustainable manufacturing practices. Prod. Plan. Control 2012, 23, 354-376. [CrossRef]

7. Solaimani, S.; Sedighi, M. Toward a holistic view on lean sustainable construction: A literature review. J. Clean. Prod. 2020, 248, 1-14. [CrossRef]

8. Joshi, Y.; Rahman, Z. Consumers' sustainable purchase behaviour: Modeling the impact of psychological factors. Ecol. Econ. 2019, 159, 235-243. [CrossRef]

9. Waheed, A.; Zhang, Q.; Rashid, Y.; Tahir, M.S.; Zafar, M.W. Impact of green manufacturing on consumer ecological behavior: Stakeholder engagement through green production and innovation. Sustain. Dev. 2020, 5, 1395-1403. [CrossRef]

10. Liu, G.; Shah, R.; Schroeder, R.G. Linking work design to mass customisation: A sociotechnical systems perspective. Decis. Sci. 2006, 37, 519-545. [CrossRef]

11. Piller, F.T. Mass customization: Reflections on the state of the concept. Int. J. Flex. Manuf. Sys. 2004, 16, 313-334. [CrossRef]

12. Duray, R. Mass customisation origins: Mass or custom manufacturing? Int. J. Oper. Prod. Manag. 2002, 22, 314-328. [CrossRef]

13. Malek, J.; Desai, T.N. A systematic literature review to map literature focus of sustainable manufacturing. J. Clean. Prod. 2020, 256, 120345. [CrossRef]

14. Slaper, T.F.; Hall, T.J. The triple bottom line: What is it and how does it work. Indiana Bus. Rev. 2011, 86, 4-8.

15. Rosen, M.A.; Kishawy, H.A. Sustainable manufacturing and design: Concepts, practices and needs. Sustainability 2012, 4, 154-174. [CrossRef]

16. Gembarski, P.C.; Schoormann, T.; Schreiber, D.; Knackstedt, R.; Lachmayer, R. Effects of Mass Customisation on Sustainability: A literature-based analysis. In Customization 4.0.; Hankammer, S., Nielsen, K., Piller, F.T., Schuh, G., Wang, N., Eds.; Springer: Cham, Switzerland, 2018; pp. 285-300.

17. Moon, Y.B. Simulation modelling for sustainability: A review of the literature. Int. J. Sustain. Eng. 2017, 10, 2-19. [CrossRef]

18. Dissanayake, D.G.K. Does Mass Customization Enable Sustainability in the Fashion Industry? Fashion Industry-An Itinerary between Feelings and Technology; IntechOpen: London, UK, 2019.

19. Pourabdollahian, G.; Steiner, F. Environmental and social impacts of mass customisation: An analysis of beginning-of-life phases. In Advances in Production Management Systems. Innovative and Knowledge-Based Production Management in a Global-Local World; Grabot, B., Vallespir, B., Gomes, S., Bouras, A., Kiritsis, D., Eds.; Springer: Berlin/Heidelberg, Germany, 2014 ; pp. 526-532.

20. Modrak, V.; Soltysova, Z.; Modrak, J.; Behunova, A. Reducing impact of negative complexity on sustainability of mass customisation. Sustainability 2017, 9, 2014. [CrossRef] 
21. Brunø, T.D.; Nielsen, K.; Taps, S.B.; Jørgensen, K.A. Sustainability evaluation of mass customisation. In Advances in Production Management Systems. Sustainable Production and Service Supply Chains; Prabhu, V., Taisch, M., Kiritsis, D., Eds.; Springer: Berlin/Heidelberg, Germany, 2013; pp. 175-182.

22. Selladurai, R.S. Mass customisation in operations management: Oxymoron or reality? Omega 2004, 32, 295-300. [CrossRef]

23. Fathi, M.; Ghobakhloo, M. Enabling mass customization and manufacturing sustainability in industry 4.0 context: A novel heuristic algorithm for in-plant material supply optimization. Sustainability 2020, 12, 6669. [CrossRef]

24. Chaudhuri, A.; Gerlich, H.A.; Jayaram, J.; Ghadge, A.; Shack, J.; Brix, B.H.; Hoffbeck, L.H.; Ulriksen, N. Selecting spare parts suitable for additive manufacturing: A design science approach. Prod. Plan. Control 2020, 32, 670-687. [CrossRef]

25. Petersen, T.D.; Jørgensen, K.A.; Nielsen, K.; Taps, S.B. Is Mass Customisation sustainable? In Proceedings of the Conference on Mass Customization, Personalisation and Co-creation: Bridging Mass Customization and Open Innovation (MCPC), San Francisco, CA, USA, 16-19 November 2011.

26. Kohtala, C. Addressing sustainability in research on distributed production: An integrated literature review. J. Clean. Prod. 2015, 106, 654-668. [CrossRef]

27. Bekker, A.C.; Verlinden, J.C. Life cycle assessment of wire+ arc additive manufacturing compared to green sand casting and CNC milling in stainless steel. J. Clean. Prod. 2018, 177, 438-447. [CrossRef]

28. Faludi, J.; Bayley, C.; Bhogal, S.; Iribarne, M. Comparing environmental impacts of additive manufacturing vs traditional machining via life-cycle assessment. Rapid Prototyp. J. 2015, 21, 14-33. [CrossRef]

29. Ingarao, G.; Priarone, P.C.; Deng, Y.; Paraskevas, D. Environmental modelling of aluminium based components manufacturing routes: Additive manufacturing versus machining versus forming. J. Clean. Prod. 2018, 176, 261-275. [CrossRef]

30. Shukla, M.; Todorov, I.; Kapletia, D. Application of additive manufacturing for mass customisation: Understanding the interaction of critical barriers. Prod. Plan. Control 2018, 29, 814-825. [CrossRef]

31. Tziantopoulos, K.; Tsolakis, N.; Vlachos, D.; Tsironis, L. Supply chain reconfiguration opportunities arising from additive manufacturing technologies in the digital era. Prod. Plan. Control 2019, 30, 510-521. [CrossRef]

32. Gilmore, J.H.; Pine, B.J. The four faces of mass customisation. Harv. Bus. Rev. 1997, 75, 91-102.

33. Duray, R.; Ward, P.T.; Milligan, G.W.; Berry, W.L. Approaches to mass customisation: Configurations and empirical validation. J. Oper. Manag. 2000, 18, 605-625. [CrossRef]

34. Ulrich, K.; Tung, K. Fundamentals of product modularity. In Proceedings of the ASME Winter Annual Meeting Symposium on Issues in Design Manufacturing Integration, Atlanta, GA, USA, November 1991.

35. Potstada, M.; Parandian, A.; Robinson, D.K.; Zybura, J. An alignment approach for an industry in the making: DIGINOVA and the case of digital fabrication. Technol. Forecast. Soc. Chang. 2016, 102, 182-192. [CrossRef]

36. Salkin, C.; Oner, M.; Ustundag, A.; Cevikcan, E. A conceptual framework for Industry 4.0. In Industry 4.0: Managing the Digital Transformation; Ustundag, A., Cevikcan, E., Eds.; Springer: Cham, Switzerland, 2018; pp. 3-23.

37. Huang, S.H.; Liu, P.; Mokasdar, A.; Hou, L. Additive manufacturing and its societal impact: A literature review. Int. J. Adv. Manuf. Technol. 2013, 67, 1191-1203. [CrossRef]

38. Kolossov, S.; Boillat, E.; Glardon, R.; Fischer, P.; Locher, M. 3D FE simulation for temperature evolution in the selective laser sintering process. Int. J. Mach. Tools Manuf. 2004, 44, 117-123. [CrossRef]

39. Levy, G.N.; Schindel, R.; Kruth, J.P. Rapid manufacturing and rapid tooling with layer manufacturing (LM) technologies, state of the art and future perspectives. CIRP Ann. 2003, 52, 589-609. [CrossRef]

40. Petrovic, V.; Vicente Haro Gonzalez, J.; Jordá Ferrando, O.; Delgado Gordillo, J.; Ramón Blasco Puchades, J.; Portolés Griñan, L. Additive layered manufacturing: Sectors of industrial application shown through case studies. Int. J. Prod. Res. 2011, 49, 1061-1079. [CrossRef]

41. Baumers, M.; Tuck, C.; Bourell, D.L.; Sreenivasan, R.; Hague, R. Sustainability of additive manufacturing: Measuring the energy consumption of the laser sintering process. Part B J. Eng. Manuf. 2011, 225, 2228-2239. [CrossRef]

42. Beyca, O.F.; Hancerliogullari, G.; Yazici, I. Additive manufacturing technologies and applications. In Industry 4.0: Managing the Digital Transformation; Ustundag, A., Cevikcan, E., Eds.; Springer: Cham, Switzerland, 2018; pp. 217-234.

43. Krajcarz, D. Comparison metal water jet cutting with laser and plasma cutting. Procedia Eng. 2014, 69, 838-843. [CrossRef]

44. Altintas, Y.; Ber, A.A. Manufacturing automation: Metal cutting mechanics, machine tool vibrations, and CNC design. Appl. Mech. Rev. 2001, 54, 77-96. [CrossRef]

45. Bawa, H.S. Manufacturing Processes-II; Tata McGraw-Hill Education: New Delhi, India, 2004.

46. Deiab, I. On energy efficient and sustainable machining through hybrid processes. Mater. Manuf. Process. 2014, 29, 1338-1345. [CrossRef]

47. Mognol, P.; Lepicart, D.; Perry, N. Rapid prototyping: Energy and environment in the spotlight. Rapid Prototyp. J. 2006, 12, 26-34. [CrossRef]

48. Singh, K.; Sultan, I.A. A computer-aided sustainable modelling and optimisation analysis of CNC milling and turning processes. J. Manuf. Mater. Process. 2018, 2, 65-79.

49. Sreenivasan, R.; Goel, A.; Bourell, D.L. Sustainability issues in laser-based additive manufacturing. Phys. Procedia 2010, 5, 81-90. [CrossRef]

50. Jayal, A.D.; Badurdeen, F.; Dillon, O.W., Jr.; Jawahir, I.S. Sustainable manufacturing: Modeling and optimisation challenges at the product, process and system levels. CIRP J. Manuf. Sci. Technol. 2010, 2, 144-152. [CrossRef] 
51. Priarone, P.C.; Ingarao, G. Towards criteria for sustainable process selection: On the modelling of pure subtractive versus additive/subtractive integrated manufacturing approaches. J. Clean. Prod. 2017, 144, 57-68. [CrossRef]

52. Jiang, Q.; Liu, Z.; Li, T.; Cong, W.; Zhang, H.C. Emergy-based life-cycle assessment (Em-LCA) for sustainability assessment: A case study of laser additive manufacturing versus CNC machining. Int. J. Adv. Manuf. Technol. 2019, 102, 4109-4120. [CrossRef]

53. Nyamekye, P.; Leino, M.; Piili, H.; Salminen, A. Overview of sustainability studies of CNC machining and LAM of stainless steel Phys. Procedia 2015, 78, 367-376. [CrossRef]

54. Law, A.M. Simulation Modeling and Analysis, 5th ed.; McGraw-Hill: New York, NY, USA, 2000.

55. Johannesson, P.; Perjons, E. An Introduction to Design Science, 1st ed.; Springer: Cham, Switzerland, 2014.

56. Scott, M.L. Programming Language Pragmatics; Morgan Kaufmann: San Francisco, CA, USA, 2000.

57. Mintzberg, H. Generic strategies: Toward a comprehensive framework. Adv. Strateg. Manag. 1988, 5, 1-67.

58. Löfgren, B.; Tillman, A.M. Relating manufacturing system configuration to life-cycle environmental performance: Discrete-event simulation supplemented with LCA. J. Clean. Prod. 2011, 19, 2015-2024. [CrossRef]

59. Wikner, J.; Rudberg, M. Introducing a customer order decoupling zone in logistics decision-making. Int. J. Logist. Res. Appl. 2005, 8, 211-224. [CrossRef]

60. Böckin, D.; Tillman, A.M. Environmental assessment of additive manufacturing in the automotive industry. J. Clean. Prod. 2019, 226, 977-987. [CrossRef]

61. Ford, S.; Despeisse, M. Additive manufacturing and sustainability: An exploratory study of the advantages and challenges. J. Clean. Prod. 2016, 137, 1573-1587. [CrossRef]

62. Duflou, J.R.; Sutherland, J.W.; Dornfeld, D.; Herrmann, C.; Jeswiet, J.; Kara, S.; Hauschild, M.; Kellens, K. Towards energy and resource efficient manufacturing: A processes and systems approach. CIRP Ann. 2012, 61, 587-609. [CrossRef]

63. Kunovjanek, M.; Knofius, N.; Reiner, G. Additive manufacturing and supply chains-A systematic review. Prod. Plan. Control 2020, 1-21. [CrossRef]

64. Ribeiro, I.; Matos, F.; Jacinto, C.; Salman, H.; Cardeal, G.; Carvalho, H.; Godina, R.; Peças, P. Framework for life cycle sustainability assessment of additive manufacturing. Sustainability 2020, 12, 929. [CrossRef]

65. Solaimani, S.; van der Veen, J. Open supply chain innovation: An extended view on supply chain collaboration. Supply Chain Manag. 2021. (forthcoming). [CrossRef]

66. Solaimani, S.; Gulyaz, E.; van der Veen, J.A.; Venugopal, V. Enablers and inhibitors of collaborative supply chains: An integrative framework. In Proceedings of the Production and Operations Management Society (POMS), Washington, DC, USA, 8-11 May 2015.

67. Iqbal, A.; Zhao, G.; Suhaimi, H.; He, N.; Hussain, G.; Zhao, W. Readiness of subtractive and additive manufacturing and their sustainable amalgamation from the perspective of Industry 4.0: A comprehensive review. Int. J. Adv. Manuf. Technol. 2019, 111, 2475-2498.

68. Buer, S.V.; Strandhagen, J.O.; Chan, F.T. The link between Industry 4.0 and lean manufacturing: Mapping current research and establishing a research agenda. Int. J. Prod. Res. 2018, 56, 2924-2940. [CrossRef]

69. Chiarini, A.; Belvedere, V.; Grando, A. Industry 4.0 strategies and technological developments. An exploratory research from Italian manufacturing companies. Prod. Plan. Control 2020, 31, 1385-1398. [CrossRef]

70. Solaimani, S.; van der Veen, J.; Sobek II, D.K.; Gulyaz, E.; Venugopal, V. On the application of Lean principles and practices to innovation management. TQM J. 2019, 31, 1064-1092. [CrossRef] 